\title{
Species diversity defends against the invasion of Nile tilapia (Oreochromis niloticus)
}

\author{
Dang E. Gu$u^{(1)}$, Du. Luo(1), Meng. Xu(1), Guang M. Ma ${ }^{(1),(2)}$, Xi D. Mu(1), \\ Jian R. Luo(1), Yin C. Hu ${ }^{(1), \star}$ \\ Received January 23, 2014 \\ Revised April 2, 2014 \\ Accepted April 8, 2014
}

\section{ABSTRACT}

Key-words:

Nile tilapia

(Oreochromis

niloticus),

biodiversity

resistance,

biological

invasion,

species

richness,

biomass

\begin{abstract}
Nile tilapia (Oreochromis niloticus) is one of the most widely cultured species globally and has successfully colonized much of the world. Despite numerous studies of this exotic species, how differences in native communities mitigate the consequences of Nile tilapia invasion is unknown. Theory predicts that communities that are more diverse should be more resistant to exotic species, an effect that is referred to as "biotic resistance", but these effects are spatially dependent and organismspecific. Field surveys and laboratory experiments were conducted to test the theory of "biotic resistance" and ascertain the relationship between native species richness and the invasion of Nile tilapia. In the field, we found that as native species richness increased, the biomass of Nile tilapia was significantly reduced. Consistent with results from the field, our manipulative experiment indicated that the growth of Nile tilapia was negatively related to native species richness. Thus, our study supports the theory of "biotic resistance" and suggests that species biodiversity represents an important defense against the invasion of Nile tilapia.
\end{abstract}

RÉSUMÉ

La diversité des espèces protège contre l'invasion du tilapia du Nil (Oreochromis niloticus)

Mots-clés :

Tilapia du Nil (Oreochromis niloticus), résistance au stress biotique, invasion biologique, richesse spécifique, biomasse
Le tilapia du Nil (Oreochromis niloticus) est l'une des espèces les plus largement élevées à l'échelle mondiale et il a colonisé avec succès la plupart des pays. Malgré de nombreuses études de cette espèce exotique, comment les différences dans les communautés indigènes influencent les conséquences de l'invasion du tilapia du Nil est une donnée inconnue. La théorie prédit que les communautés qui sont plus variées devraient être plus résistantes aux espèces exotiques, un effet qui est dénommé "résistance au stress biotique ", mais ces effets sont spatialement dépendants et propres à chaque organisme. Des études de terrain et des expériences de laboratoire ont été menées afin de tester la théorie de la "résistance au stress biotique " et de déterminer la relation entre la richesse des espèces indigènes et l'invasion du tilapia du Nil. Sur le terrain, nous avons constaté que, quand la richesse des espèces indigènes augmente, la biomasse du tilapia du Nil est considérablement réduite. Conformément aux résultats sur le terrain, notre expérience

(1) Pearl River Fisheries Research Institute, Chinese Academy of Fishery Sciences, Key Laboratory of Tropical and Subtropical Fishery Resource Application and Cultivation, Ministry of Agriculture, Guangzhou, Guangdong 510380, P.R. China

(2) College of Fisheries and Life Science, Shanghai Ocean University, Shanghai 201306, P.R. China

* Corresponding author: huyc22@163.com 
de manipulation indique que la croissance du tilapia du Nil est négativement associée à la richesse des espèces indigènes. Ainsi, notre étude confirme la théorie de la « résistance au stress biotique » et suggère que la biodiversité des espèces représente un important moyen de défense contre l'invasion du tilapia du Nil.

\section{INTRODUCTION}

Biological invasion is one of the most severe ecological and economic problems and one of the most important causes of the global biodiversity crisis (Davies et al., 2010; Lowe et al., 2012). The introduction of exotic species can cause economic and ecological damage through competition, predation, parasitism, hybridization and habitat alteration (Carey and Wahl, 2010; Giannetto et al., 2012). Ecologists widely agree that invasive fish strongly impact native aquatic ecosystems and native fish fauna (Martin et al., 2010a; Giannetto et al., 2012). Although studies on invasive species abound, there is a general lack of understanding of how differences in the properties of native communities can both limit the success of invaders and mitigate their deleterious effects (Kennedy et al., 2002; Carey and Wahl, 2010). Why some communities are more readily invaded than others is unknown. Therefore, studies of the invasibility of communities are of general importance (Davies et al., 2010).

Native communities prevent invasions through a variety of mechanisms, and these mechanisms are referred to as "biotic resistance" (Elton, 1958). The theory of biotic resistance predicts that communities with greater diversity will inhibit invasive species, which is supported by both theory and experimental studies (Elton, 1958; Stachowicz et al., 1999; Kennedy et al., 2002; Tilman, 2004; Davies et al., 2005, 2010; Carey and Wahl, 2010). In many studies, biotic resistance refers to the ability of a natural community to resist the establishment of invaders (Stohlgren et al., 1999; Levine, 2000; Meador et al., 2003; Davies et al., 2005; Davies et al., 2010; Kimbro et al., 2013). However, many communities have already been invaded; thus, understanding the effects of native diversity on established invaders is also necessary (Emery and Gross, 2006; Carey and Wahl, 2010). Native species diversity has also been shown to decrease the growth and biomass of invaders (Carey and Wahl, 2010; Stachowicz et al., 2002; Kennedy et al., 2002). Thus, exploring whether differences in native diversity influence the invader's biomass and growth will also test the theory of biotic resistance (Pyšek et al., 2008). Furthermore, most studies have been conducted on plants and sessile fauna; few studies have been performed on invasive consumers, especially in aquatic ecosystems, although many communities are composed of a large proportion of invasive fish species (Stachowicz et al., 2006; Moyle and Marchetti, 2006; Carey and Wahl, 2010).

Nile tilapia (Oreochromis niloticus Linnaeus), which is native to Africa, has become an important component of inland fisheries and aquaculture in tropical and subtropical countries (Martin et al., 2010a). Nile tilapia is popular in aquaculture because this species can tolerate a wide range of environmental conditions, has flexible habitat requirements, reproduces shortly after birth, grows rapidly, and has aggressive and omnivorous feeding habits (Grammer et al., 2012). These traits make them a "model invader" (Perez et al., 2006) and have likely facilitated their success as an invasive species (Peterson et al., 2005). Published reports indicate that Nile tilapia has successfully colonized many regions of the world (Costa-Pierce, 2003; Peterson et al., 2005; Martin et al., 2010a; Grammer et al., 2012; Gu et al., 2012a). Nile tilapia can reduce local biodiversity by preying on the eggs of other species and competing with native species for food resources and habitat (Martin et al., 2010a). Nile tilapia can also affect photosynthesis and primary production in ecosystems by reducing the amount of available light in the water as a result of their digging behavior (Peterson et al., 2005).

In the main rivers of South China, such as the Pearl River (with large tributaries that include the Xijiang River, Beijiang River and Dongjiang River), Hanjiang River and Jianjiang River, Nile tilapia populations have become established in the field because of their ability to overwinter and reproduce in natural waters (Gu et al., 2012a; Gu et al., 2012b). Studies of the 


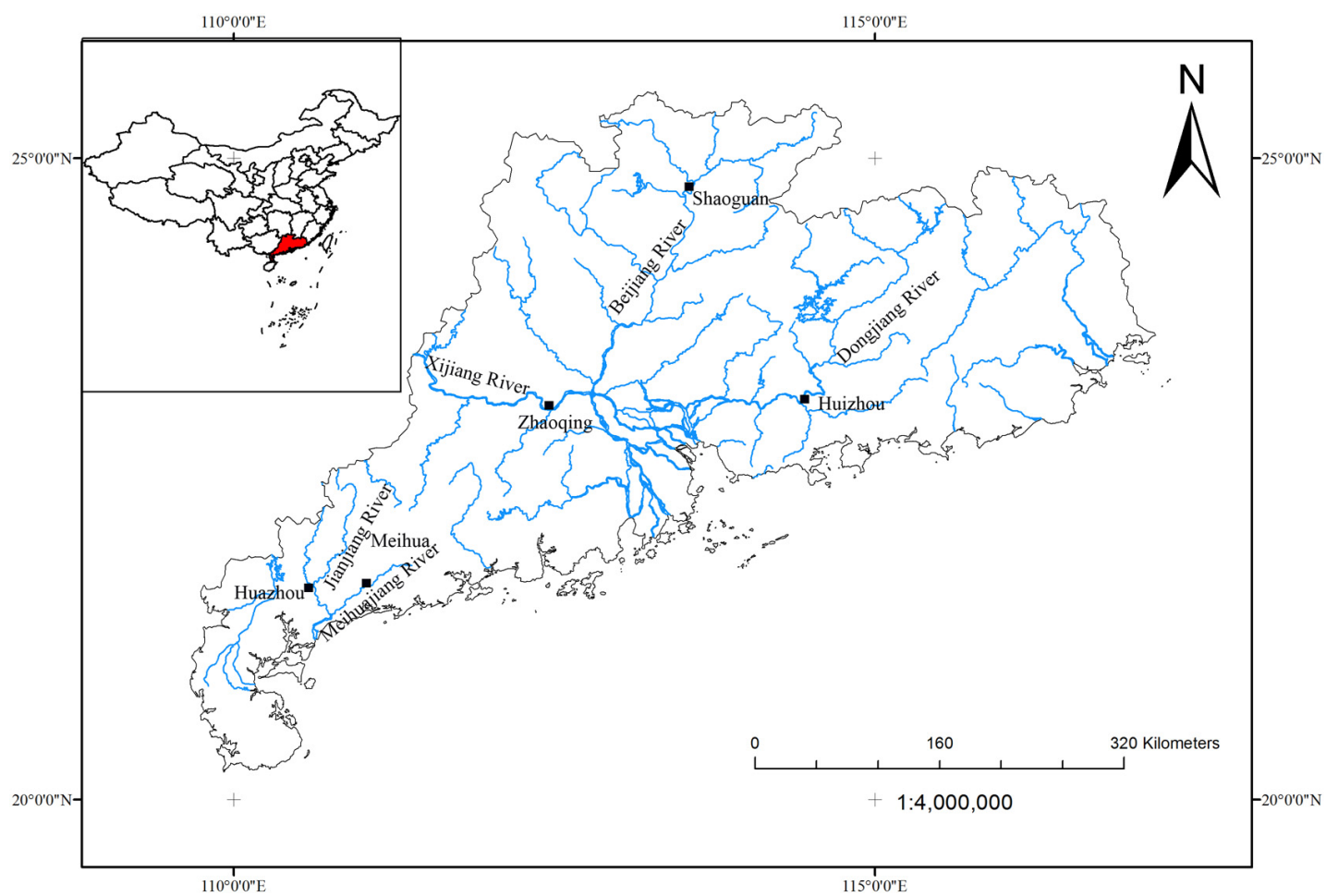

Figure 1

Geographic distribution of the sampling locations in Guangdong Province, China (घ).

mechanisms underlying the invasion of Nile tilapia will be beneficial for predicting and managing this invasion. Therefore, the relationship between Nile tilapia and the biodiversity of communities is an important topic of research.

We focus on addressing how native communities affect Nile tilapia populations that have been established, rather than how they influence tilapia's establishment or how Nile tilapia impacts native communities. Herein, we describe the results of a field survey and manipulative experiments to assess whether higher biodiversity defends against the invasion of Nile tilapia.

\section{METHODS}

\section{> EXPERIMENT 1: FIELD SURVEY}

To study the relationship between biodiversity and the biomass of Nile tilapia in the field, our survey was carried out at five sites along the Pearl River and Jianjiang River, which are located in Guangdong Province, South China. The Pearl River is used as a general term for the Xijiang River (West River), Beijiang River (North River), and Dongjiang River (East River) and is China's third longest river $(2400 \mathrm{~km})$ and second largest by volume. The Jianjiang River is another important river in South China, whose basin is also an important producer of Nile tilapia, similar to the Pearl River. Among the five sites, three (Zhaoqing, Shaoguan and Huizhou) are located in the Pearl River (one each in the Xijiang, Dongjiang and Beijiang Rivers). The other two sites (Meihua and Huazhou), belonging to the Jianjiang River basin, are located along the Meihuajiang and Jianjiang Rivers, respectively (Figure 1).

Fish were sampled 16 times in all between August 2011 and October 2013. Each sampling lasted two days, all fishing boats at each site were investigated, and each site was surveyed 3-4 times (Meihua: August 2011, October 2011, June 2012; Huazhou: September 2011, October 2011, June 2012; Shaoguan: March 2012, November 2012, March 2013, August 2013; 
Huizhou: August 2012, March 2013, October 2013; and Zhaoqing: March 2012, June 2013, August 2013). All samples were collected from the fish industry, and no protected species were sampled. In this study, fish were primarily caught with gillnets and shrimp pots and all surveys were conducted using the same fishing gear. All catch was weighed with the help of the fishermen in the surveys. Fishes were then identified and the number of species quantified. All Nile tilapia were collected and weighed. In the tilapia populations, many offspring are hybrids of Nile tilapia and other tilapia species. In this study, such hybrids were counted as Nile tilapia.

The following data were collected during each survey at each site: (1) total weight of all fishes collected, (2) total weight of Nile tilapia collected, and (3) species richness (species number). The weight ratio and the total weight of Nile tilapia were used as a proxy of Nile tilapia biomass. The weight ratio of Nile tilapia was calculated with the following equation:

$$
R_{\text {Nile tilapia }}=W_{\text {Nile tilapia }} / W_{\text {All fishes }},
$$

where $W_{\text {Nile tilapia }}$ refers to the total weight of Nile tilapia caught at each site and $W_{\text {All fishes }}$ refers to the total weight of all fishes caught at each site.

$R_{\text {Nile tilapia }}$ was log-transformed, and linear regressions were used to determine whether species richness impacts $R_{\text {Nile tilapia }}$ and the total weight of Nile tilapia in all of the surveys at all sites. An ANOVA F-test was used to verify the significance of the regression equations. Statistical analyses were performed using SPSS16.0, and the results are considered significant at $P \leqslant 0.05$.

\section{> EXPERIMENT 2: LABORATORY EXPERIMENT}

To study the relationship between native community biodiversity and the growth of Nile tilapia, experiments were conducted from April to June 2013 in the laboratory of the Pearl River Fisheries Research Institute, Chinese Academy of Fishery Sciences, Guangzhou City, Guangdong Province, China. Seven mesocosms (450 L) were used in this experiment, each of which contained three small ecological systems $(150 \mathrm{~L})$. The mesocosms were placed outside and seeded with algae and zooplankton from a local lake $\left(900 \mathrm{~m}^{2}\right)$ two weeks prior to the start of the experiment. One-third of the water was changed each day using water from the lake.

Four native fish species were used for the diversity treatments: mud carp (Carrhina molitorella Cuvier et Valenciennes), crucian carp (Carassius auratus Linnaeus), grass carp (Ctenopharyngodon idellus Cuvier et Valenciennes) and common carp (Cyprinus carpio Linnaeus), which were abundant at all wild sites and co-occurred with Nile tilapia. Nile tilapia and the four native fishes were obtained from the Gaoyao Aquaculture Germplasm Conservation Station, Pearl River Fishery Research Institute, Chinese Academy of Fishery Sciences.

The one-species richness level included Nile tilapia only. Three different two-species richness levels were used: Nile tilapia and mud carp, Nile tilapia and crucian carp, and Nile tilapia and grass carp. The three-species level included Nile tilapia, mud carp and crucian carp, and the four-species level included Nile tilapia, mud carp, crucian carp and grass carp. The fivespecies richness level included Nile tilapia, mud carp, crucian carp, grass carp and common carp. The experimental design was substitutive; thus, the number of Nile tilapia and the total numbers of each species were the same in each group. All treatments were replicated three times (Griffen, 2006; Martin et al., 2010b).

There were 60 individuals in each mesocosm and 20 fishes in each ecological system. Juvenile fishes were used with the following body weights: Nile tilapia, $1.90 \pm 0.41 \mathrm{~g}$; mud carp, $2.35 \pm 0.28 \mathrm{~g}$; crucian carp, $2.44 \pm 0.48 \mathrm{~g}$; grass carp, $3.47 \pm 0.43 \mathrm{~g}$; and common carp, $2.18 \pm 0.23$. The weights of Nile tilapia were measured at the beginning of the experiment and two weeks later, when the experiment ended. In each small ecological system, three fish were weighed together to reduce the effect of random error.

The relative growth ((final $\mathrm{g}$ - initial $\mathrm{g}$ )/initial g) of Nile tilapia and the other four species was calculated and averaged for each mesocosm (Carey and Wahl, 2010). The relative growth of Nile tilapia was compared across the richness treatments (one, two, three, four and five) 


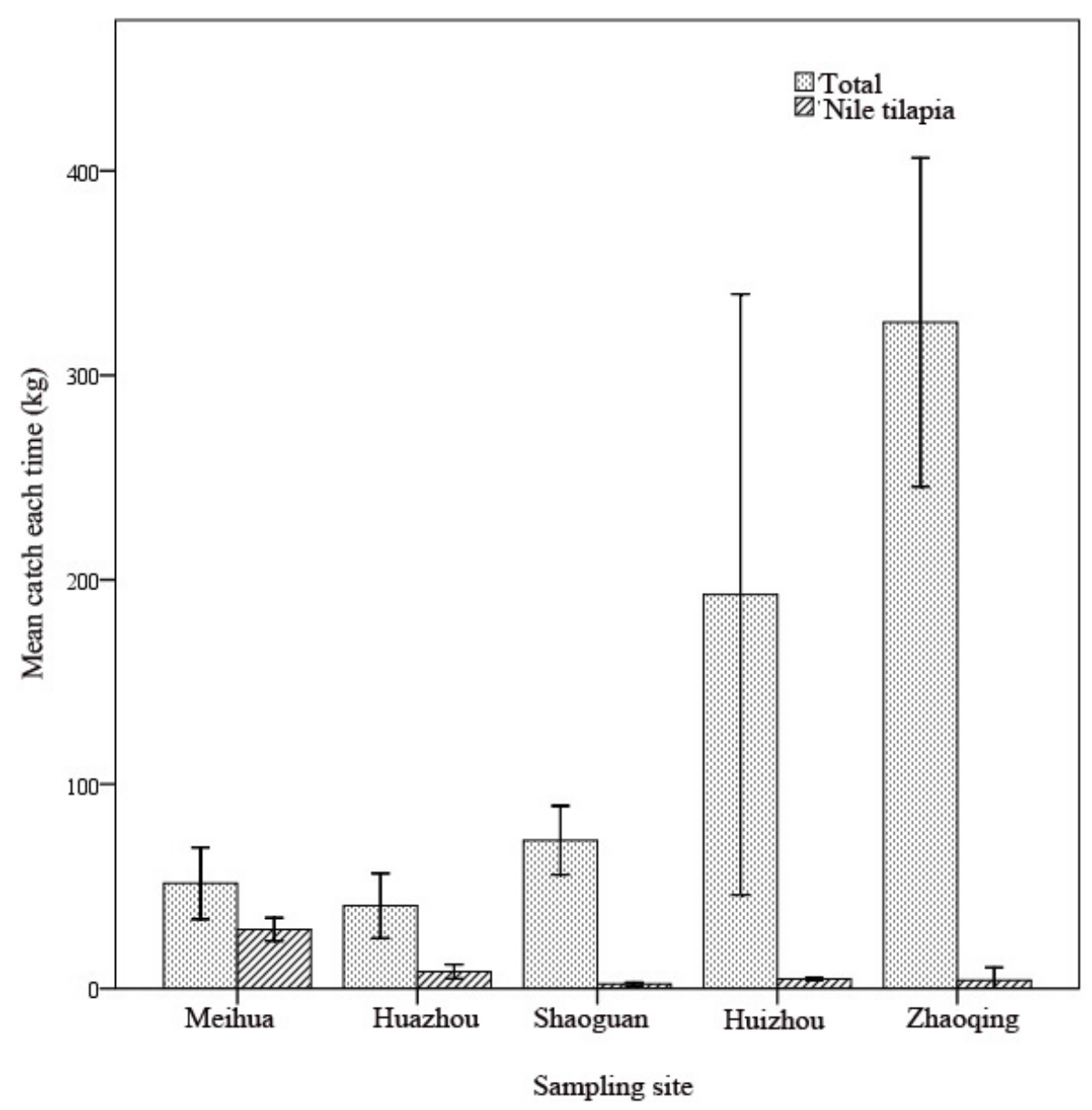

Figure 2

Mean $( \pm S D)$ total catch and Nile tilapia catch during each survey at 5 sites.

with a one-way analysis of variance (ANOVA). The relationship between the relative growth of Nile tilapia and species richness was analyzed using linear and logistic regressions. All of the statistical analyses were conducted using SPSS16.0, and the results were considered significant at $P \leqslant 0.05$.

The use of the fishes in this study was approved by the aquatic animal research committee at the Pearl River Fisheries Research Institute. All experimental procedures that were conducted conformed with the institutional guidelines for the care and use of laboratory animals at the Pearl River Fisheries Research Institute, Chinese Academy of Fishery Sciences, Guangzhou, Guangdong, China. All experiments were also performed according to the Chinese Association for Laboratory Animal Sciences guidelines for the care and use of laboratory animals (IACUC). In our experiments, fishes were farmed in freshwater from the natural lake and they were only weighed twice. After the experiment, fishes were returned back to the ponds where they came from with no injuries or mortality.

\section{RESULTS}

\section{$>$ EXPERIMENT 1}

In the surveys of five sites, the total catch in each survey in Meihua, Huazhou, Shaoguan, Huizhou and Zhaoqing was, on average, 51.50, 40.50, 72.48, 192.77 and $325.93 \mathrm{~kg}$, respectively, and the mean total catch of Nile tilapia was $28.93,8.26,2.21,4.68$ and $4.08 \mathrm{~kg}$, respectively (Figure 2). 


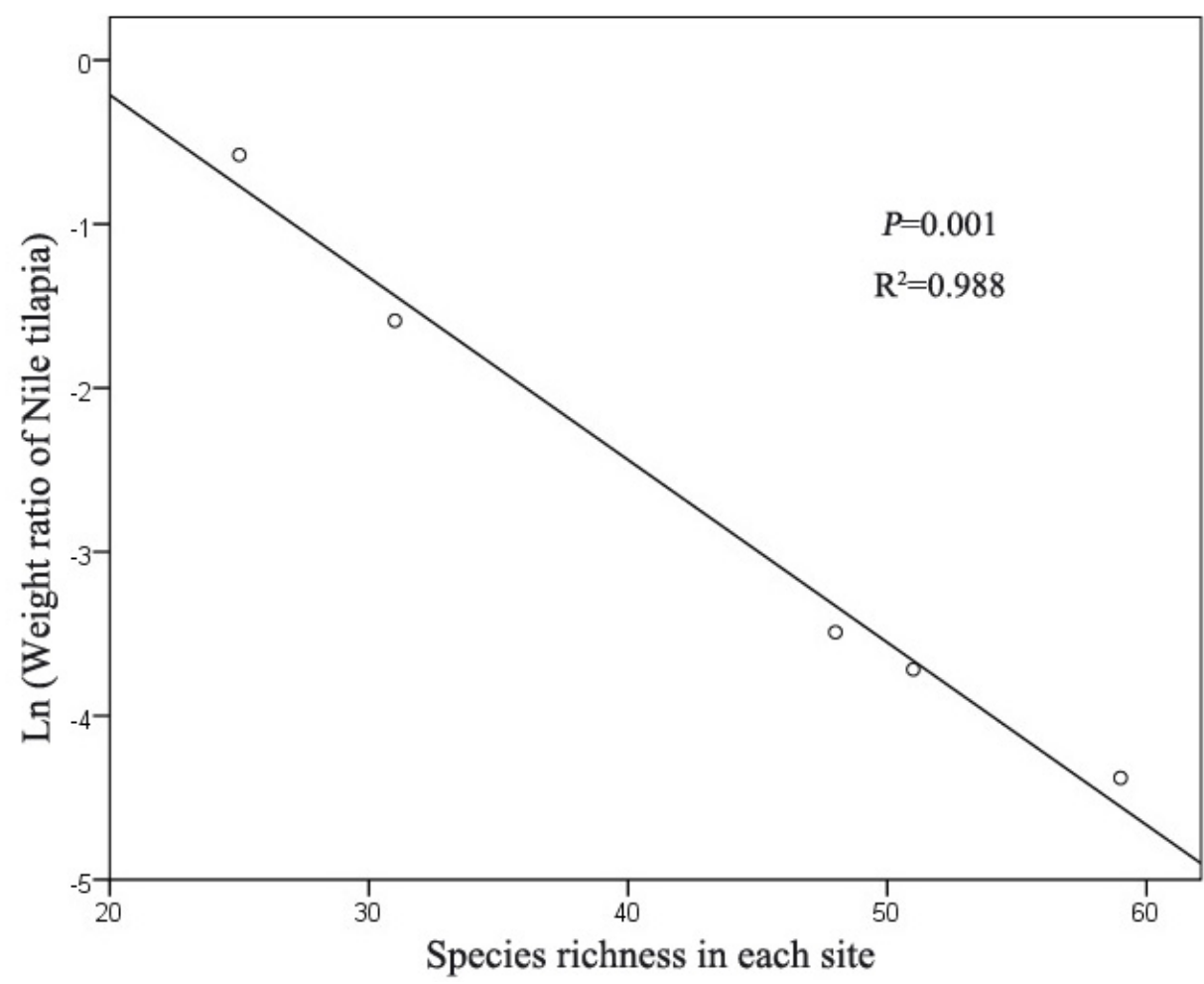

Figure 3

Relationship between species number and the weight ratio of Nile tilapia at 5 sites.

Fish species numbers in Meihua, Huazhou, Shaoguan, Huizhou and Zhaoqing were 59, 51, 48,32 and 25, respectively, and the weight ratio of Nile tilapia at each site was significantly and negatively related to the number of species (linear regression $F=254.8, P=0.001$, $R^{2}=0.988$ ) (Figure 3).

The relationship between species richness and the weight ratio of Nile tilapia in all 16 surveys was also analyzed. The weight ratio of Nile tilapia in each survey was significantly and negatively related to the number of species (linear regression: $F=55.14, P<0.001, R^{2}=0.798$ ) (Figure 4).

The total catch of Nile tilapia was also negatively related to the number of species in all 16 surveys (liner regression: $F=11.83, P=0.004, R^{2}=0.458$ ) (Figure 5).

\section{> EXPERIMENT 2}

The relative growth of Nile tilapia varied significantly among richness treatments $(F(4,16)=$ 25.56, $P<0.001)$. The relative growth in the one-, two-, three-, four- and five-species treatments was $1.98 \pm 0.11,1.02 \pm 0.27,0.89 \pm 0.19,0.64 \pm 0.09$ and $0.38 \pm 0.05$ grams, respectively. Species richness had significant negative effects on the growth of Nile tilapia (linear regression, $F=39.02, P<0.001, R^{2}=0.673$ ) (Figure 6).

\section{DISCUSSION}

Characteristics of invaders, extrinsic factors of the environment, and the structure of native communities can influence the progression of biological invasions (Holle and Simberloff, 2005; Carey and Wahl, 2010). In addition, characteristics of invaders and, in particular, their ability to modify their environment can also affect their success (Gonzalez et al., 2008). The characteristics of Nile tilapia that promote their successful invasion include their ability to tolerate 
Dang E. Gu et al.: Knowl. Managt. Aquatic Ecosyst. (2014) 414, 07

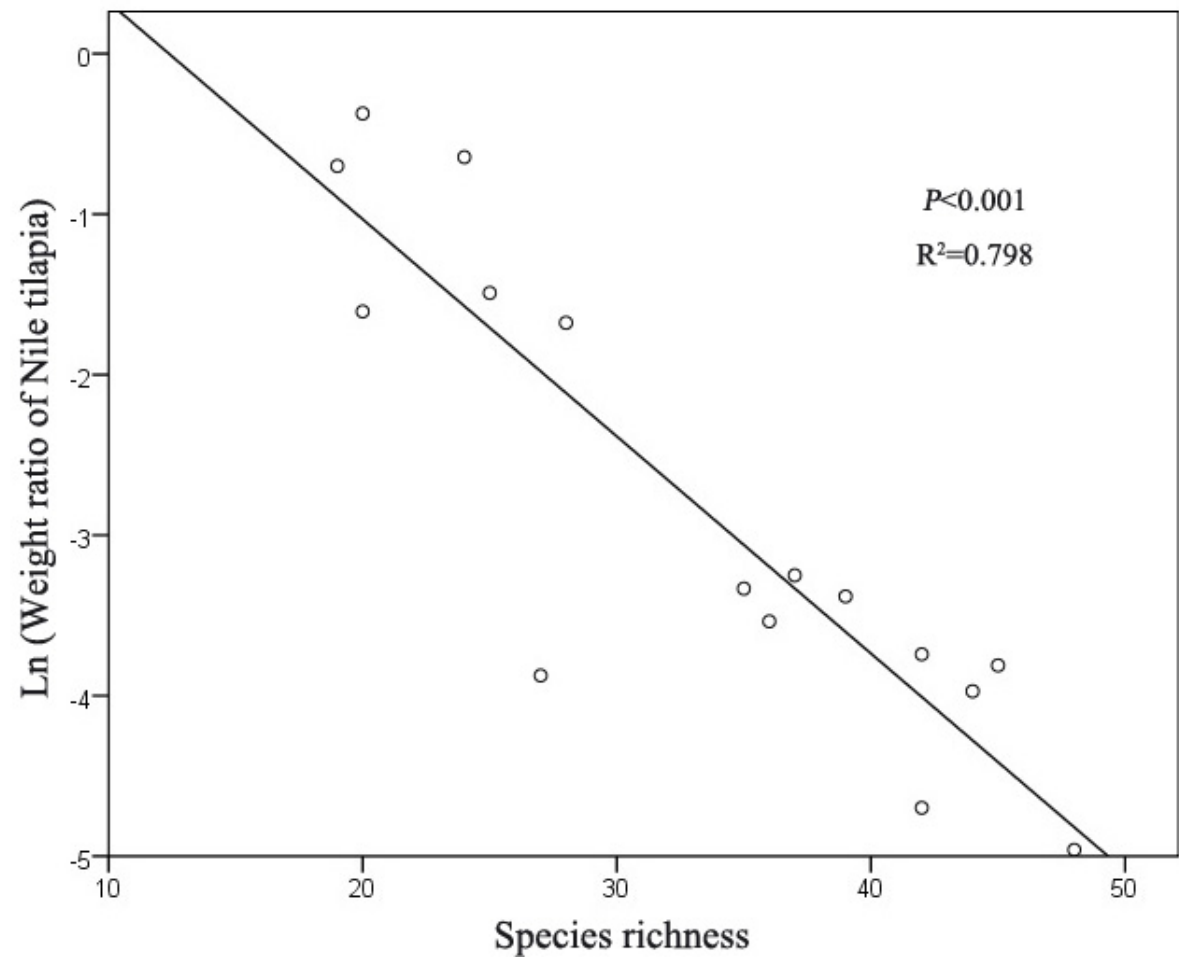

Figure 4

Relationship between species number and the weight ratio of Nile tilapia from 16 surveys.

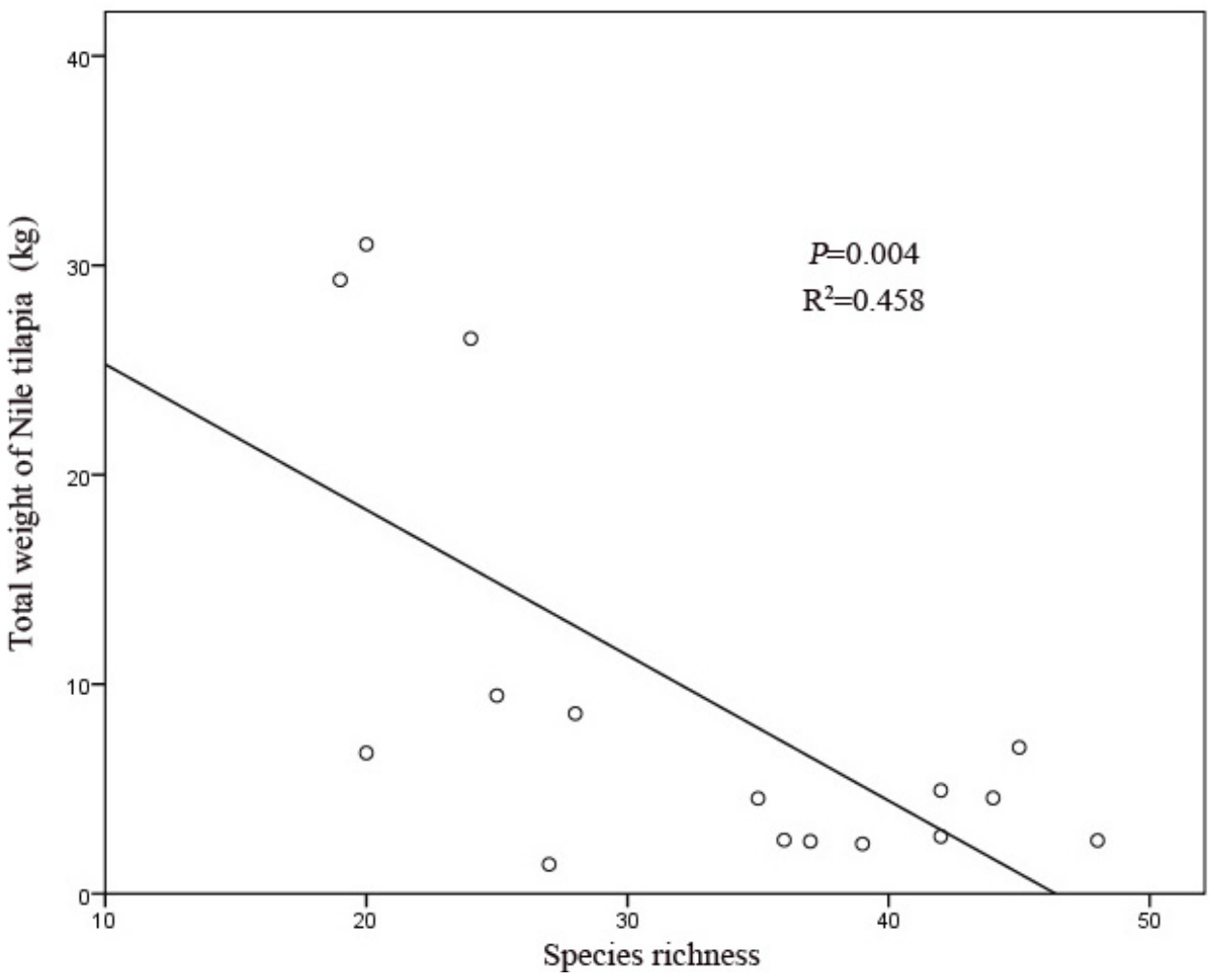

Figure 5

Relationship between species richness and the total weight of Nile tilapia from 16 surveys. 


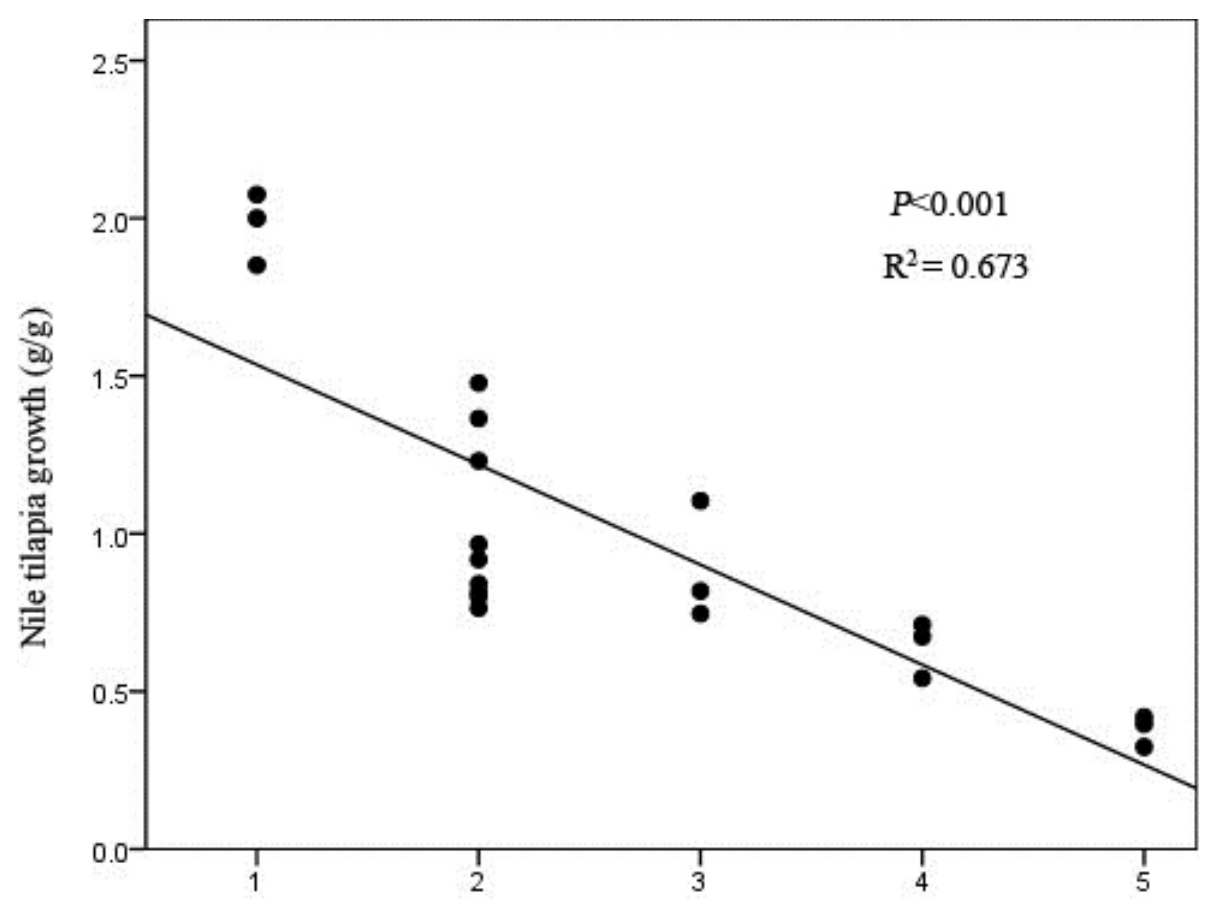

Species richness

\section{Figure 6}

Relative growth of Nile tilapia across different levels of species richness.

a wide range of environmental conditions, their flexible habitat requirements, reproductive strategies and fast growth (Grammer et al., 2012). Salinity and temperature have been considered to be major factors that limit the distribution of tilapia populations (Shipton et al., 2008). Previously, researchers have argued that Nile tilapia and other tilapia species have not successfully invaded temperate environments because they could not survive cold winter temperatures (Grammer et al., 2012); however, recent evidence suggests that low temperatures are unlikely to limit the year-round survival of tilapia (Hargreaves, 2000; Peterson et al., 2005; Martin et al., 2010a; Gu et al., 2012a; Gu et al., 2012b). In addition, all sampling points in this study were from freshwater ecosystems, so salinity should not affect the results of this study. The characteristics of Nile tilapia and environmental factors in our study suggest that abiotic characteristics are not critical factors determining their invasion success. Instead, the structure of native communities may be important.

The relationship between the structure of native communities and invasion success has been discussed in many studies (Elton, 1958; Stachowicz et al., 1999, 2002; Stohlgren et al., 1999; Levine et al. 1999; Levine, 2000; Kenney et al., 2002; Richardson et al., 2005; Davies et al., 2005, 2010; Kimbro et al., 2013). However, the relative contribution of resident diversity to invasion resistance varies across different spatial scales (Kenney et al., 2002; Davies et al., 2010). Studies suggest that species loss on small scales may reduce invasion resistance (Elton, 1958; Stachowicz et al., 1999, 2002; Levine, 2000; Kenney et al., 2002; Davies et al., 2005, 2010; Kimbro et al., 2013). In addition, resources are used more completely in diverse communities on small spatial scales (Kenney et al., 2002; Tilman, 2004; Stachowicz et al., 1999, 2006), and native species are more likely to resist invasion because they are likely to occupy similar niches (Davies et al., 2010). Spatial scales can also affect invaders through competition, predation, and pathogen and disease resistance (Kenney et al., 2002; Davies et al., 2010). Most experimental studies, which are necessarily conducted on small scales, support the idea that species richness decreases invasion success (Knops et al., 1999; Stachowicz et al., 1999, 2006; Levine, 2000; Kenney et al., 2002). However, there is also convincing evidence that the relationship between the diversity of native and invading species 
is positive when measured on large spatial scales (Stohlgren et al., 1999; Levine et al., 1999; Levine, 2000; Richardson et al., 2005; Davies et al., 2005, 2010). On large scales, spatial heterogeneity in the environment leads to high species diversity and is conducive to the invasion of exotic species because of the greater resources, temperature and nutritional heterogeneity of large-scale environments (Levine et al., 1999; Davies et al., 2010). Furthermore, the spatial heterogeneity and extensive supply of invaders makes the most diverse communities more likely to be invaded because the characteristics that favor high native diversity also favor high exotic diversity, rather than high levels of native biodiversity per se favoring high exotic diversity (Levine et al., 1999; Richardson et al., 2005; Davies et al., 2005, 2010; Martin et al., 2012). Most studies that support this idea are observational studies, and most have investigated the relationship between populations of exotic fish and native diversity (Stohlgren et al., 1999; Levine et al., 1999; Levine, 2000; Davies et al., 2005, 2010). Furthermore, most studies supporting biodiversity resistance have examined the relationship between exotic biomass and native diversity (Knops et al., 1999; Stachowicz et al., 1999, 2002, 2006; Levine, 2000; Kenney et al., 2002). However, previous studies have focused on how native communities have affected the successful establishment of invaders rather than how native communities have affected the persistence of invaders after their establishment (Levine et al., 1999; Kimbro et al., 2013), despite the fact that the principles of biodiversity resistance also apply to established invaders. Therefore, biomass studies have explained resistance not only during invasion but also after the invader has been established. In our study, we used experiments in mesocosms on small spatial scales and field surveys on large spatial scales to explain whether native diversity affects the invasion of Nile tilapia.

In our survey of the five traditional fishing locations, most species at each site were collected according to the resource survey at the same sites (Song, 1992; Li et al., 2009; Liu et al., 2011). The species number and the total catch in each survey were more than 19 and 33.5, respectively. Therefore, these data are useful for explaining the relationship between species richness and Nile tilapia biomass.

In our surveys, we found that species richness was significantly negatively related to the weight ratio of Nile tilapia and the total catch of Nile tilapia in all surveys and sites (Figures 3-5). Our results showed that high diversity reduced the biomass of Nile tilapia because the total weight and the weight ratio of Nile tilapia were limited. Decreased invader biomass has also been observed in other biodiversity systems. For example, species richness had negative effects on the total cover of invasive plants (Kennedy et al., 2002), the percent cover of invader sea squirts was reduced by the native diversity (Stachowicz et al., 2002), and the abundance of introduced fish was negatively related to native fish species richness (Meador et al., 2002). We used the total weight and weight ratio of Nile tilapia as an indicator of the biomass of Nile tilapia, and the same results were obtained. Our results support the "biotic resistance" hypothesis because the biomass of Nile tilapia was reduced by the diversity of native species. We also suggest that higher species richness will defend against the invasion of Nile tilapia.

In our experimental study, the growth of alien Nile tilapia was also reduced by native species (Figure 6). Reduction in the growth of invasive species has also been observed in other community diversity studies. For example, higher native species richness has been shown to reduce the maximum size of invasive plants (Kennedy et al., 2002), the size of the largest individual per tussock (Levine, 2000), and the growth of invasive common carp (Carey and Wahl, 2010). Our results confirm that the decrease in the growth of invaders with native species diversity supports the hypothesis of "biotic resistance", and, more generally, this result will be useful for reducing the impact of Nile tilapia on native species and aquatic ecosystems.

Our study supports the theory of "biotic resistance" and suggests that biodiversity loss may degrade the ability of native communities to resist the invasion of Nile tilapia. When biodiversity loss promotes invasion and successful invasion further decreases biodiversity, a negative feedback cycle may be initiated, resulting in a severely impoverished global biota (Kennedy et al., 2002). Appropriate measures should be taken to protect species diversity and prevent biological invasions. 


\section{ACKNOWLEDGEMENTS}

This work was supported by funds from the Chinese Ministry of Agriculture (2130108) and Guangdong Oceanic \& Fishery Administration, China. We thank HK Zhang, SD Zhou, GY Peng, HY He and JZ Lin for their help in collecting fish samples. We also thank the reviewers for providing assistance with improving an earlier version of this manuscript.

\section{REFERENCES}

Carey M.P. and Wahl D.H., 2010. Native fish diversity alters the effects of an invasive species on food webs. Ecology, 91, 2965-2974.

Costa-Pierce B.A., 2003. Rapid evolution of an established feral tilapia (Oreochromis spp.): the need to incorporate invasion science into regulatory structures. Biol. Invasions, 5, 71-84.

Davies K.F., Cavender-Bares J. and Deacon N., 2010. Native communities determine the identity of exotic invaders even at scales at which communities are unsaturated. Divers. Distrib., 17, 35-42.

Davies K.F., Chesson P., Harrison S., Inouye B.D., Melbourne B.A. and Rice K.J., 2005. Spatial heterogeneity explains the scale dependence of the native-exotic diversity relationship. Ecology, 86, 1602-1610.

Elton C.S., 1958. The ecology of invasions. Methuen, London, UK.

Emery S. M. and Gross K. L., 2006. Dominant species identity regulates invasibility of old-field plant communities. Oikos, 115, 549-558.

Giannetto D., Carosi A., Franchi E., Ghetti L., Pedicillo G., Pompei L. and Lorenzoni M., 2012. Assessing the impact of non-native freshwater fishes on native species using relative weight. Knowl. Manag. Aquat. Ecosyst., 404, 03.

Gonzalez A., Lambert A. and Ricciardi A., 2008. When does ecosystem engineering cause invasion and species replacement? Oikos, 117, 1247-1257.

Grammer G.L., Slack W.T., Peterson M.S. and Dugo M.A., 2012. Remove from marked Records Nile tilapia Oreochromis niloticus (Linnaeus, 1758) establishment in temperate Mississippi, USA: multiyear survival confirmed by otolith ages. Aquat. Invasions, 7, 367-376.

Griffen B.D., 2006. Detecting emergent effects of multiple predator species. Oecologia, 148, 702-709.

Gu D.E., Mu X.D., Luo D., Li Y.Y., Wang X.J., Song H.M., Luo J.R. and Hu Y.C., 2012. The distribution of alien aquatic animals in the main rivers of Guangdong Province, China. J. Biosafety, 21, 272-276.

Gu D.E., Mu X.D., Luo D, Li Y.Y., Yang Y.X., Xu M. and Hu Y.C., 2012., The study of population establishment of tilapia in main rivers in Guangdong Province, China. J. Biosafety 21, 277-282.

Hargreaves J.A., 2000. Tilapia culture in the southeast United States. 60-81. In Costa-Pierce B.A., Rakocy J.E. (eds.), Tilapia Aquaculture of the Americas, volume 2. The World Aquaculture Society, Baton Rouge, Louisiana.

Holle B.V. and Simberloff D., 2005. Ecological resistance to biological invasion overwhelmed by propagule pressure. Ecology, 86, 3212-3218.

Kennedy T.A., Naeem S., Howe K.M., Knops J.M.H., Tilman D. and Reich P., 2002. Biodiversity as a barrier to ecological invasion. Nature, 417, 636-638.

Kimbro D.L., Cheng B.S. and Grosholz E.D., 2013. Biotic resistance in marine environments. Ecol. Lett., 16, 821-833.

Knops J.M.H., Tilman D., Haddad N.M., Naeem S., Mitchell C.E., Haarstad J., Ritchie M.E., Howe K.M., Reich P.B., Siemann E. and Groth J., 1999. Effects of plant species richness on invasion dynamics, disease outbreaks, insect abundances, and diversity. Ecol. Lett., 2, 286-293.

Levine J.M., 2000. Species diversity and biological invasions: relating local process to community pattern. Science, 288, 852-854.

Levine J.M. and D'Antonio C.M., 1999. Elton revisited: a review of evidence linking diversity and invasibility. Oikos, 87, 15-26.

Li J., Li X.H., Tan X.C., Li Y.F., He M.F., Luo J.R., Lin J.Z. and Su S.F., 2009. Species diversity of fish community of Provincial Xijiang River Rare Fishes Natural Reserve in Zhaoqing City, Guangdong Province. J. Lake Sci., 21, 556-562. 
Liu Y., Lin X.T., Sun J., Zhang P.F. and Chen G.Z., 2011. Fish community changes in Huizhou segment of Dongjiang river. Chinese Journal of Zoology, 46, 1-11.

Lowe M.R., Wu W., Peterson M.S., Brown-Peterson N.J., Slack W.T. and Schofield P.J., 2012. Survival, growth and reproduction of non-native Nile tilapia II: fundamental niche projections and invasion potential in the northern Gulf of Mexico. PLoS ONE, 7, e41580.

Martin C.W., and Valentine J.F., 2012. Eurasian milfoil invasion in estuaries: physical disturbance can reduce the proliferation of an aquatic nuisance species. Mar. Ecol. Prog. Ser., 449, 109-119.

Martin C.W., Valentine M.M. and Valentine J.F., 2010a. Competitive interactions between invasive Nile tilapia and native fish: the potential for altered trophic exchange and modification of food webs. PLOS ONE, 5, e14395.

Martin C.W., Fodrie F.J., Heck Jr K.L. and Mattila J., 2010b. Differential habitat use and antipredator response of juvenile roach (Rutilus rutilus) to olfactory and visual cues from multiple predators. Oecologia, 162, 893-902.

Meador M.R., Brown L.R. and Short T., 2003. Relations between introduced fish and environmental conditions at large geographic scales. Ecol. Indic., 3, 81-92.

Pe'rez J.E., Nirchio M., Alfonsi C. and Munoz C., 2006. The biology of invasions: the genetic adaptation paradox. Biol. Invasions, 8, 1115-1121.

Peterson M.S., Slack W.T. and Woodley C.M., 2005. The occurrence of nonindigenous Nile Tilapia, Oreochromis niloticus (Linnaeus) in coastal Mississippi: ties to aquaculture and thermal effluent. Wetlands, 25, 112-121.

Pyšek P., Richardson D.M., Pergl J., Jarošík V., Sixtová Z., and Weber E., 2008. Geographical and taxonomic biases in invasion ecology. Trends in Ecology \& Evolution, 23, 237-244.

Richardson D.M., Rouget M., Ralston S.J., Cowling R.M., van Rensburg B.J. and Thuiller W., 2005. Species richness of alien plants in South Africa: environmental correlates and the relationship with indigenous plant species richness. Ecoscience, 12, 391-402.

Shipton T., Tweddle D. and Watts M., 2008. ECDC 2008, Introduction of the Nile Tilapia (Oreochromis niloticus) into the Eastern Cape. A report for the Eastern Cape Development Corporation, $30 \mathrm{p}$.

Song P.L., 1992. Preliminary investigation on fish species diversity in Jianjiang River. Journal of Zhanjiang Fisheries College, 12, 83-86.

Stachowicz J.J. and Byrnes J.E., 2006. Species diversity, invasion success, and ecosystem functioning: disentangling the influence of resource competition, facilitation, and extrinsic factors. Mar. Ecol. Prog. Ser., 311, 251-262.

Stachowicz J.J., Fried H., Osman R.W. and Whitlatch R.B., 2002. Biodiversity, invasion resistance, and marine ecosystem function: reconciling pattern and process. Ecology, 83, 2575-2590.

Stachowicz J.J., Whitlatch B. and Osman R.W., 1999. Species diversity and invasion resistance in a marine ecosystem, Science, 286, 1577-1579.

Stohlgren T.J., Binkley D., Chong G.W., Kalkhan M.A., Schell L.D., Bull K.A., Otsuki Y., Newman G., and Bashkin M. and Son Y., 1999. Exotic plant species invade hot spots of native plant diversity. Ecol. Monogr., 69, 25-46.

Tilman D., 2004. Niche tradeoffs, neutrality, and community structure: a stochastic theory of resource competition, invasion, and community assembly. Proc. Nat. Acad. Sci. USA, 101, 10854-10861. 